\title{
LEARNING FROM OWN MISTAKES - A COMPARATIVE STUDY OF STUDENT DESIGN PROJECTS WORKING WITH DIFFERENT LEARNING APPROACHES
}

\author{
Markus VOß ${ }^{1}$, Hulusi BOZKURT ${ }^{1}$, Thorsten SAUER ${ }^{2}$ and Marc NUTZMANN ${ }^{2}$ \\ ${ }^{1}$ DHBW Baden-Wuerttemberg Cooperative State University Mannheim, Germany \\ ${ }^{2}$ DHBW Baden-Wuerttemberg Cooperative State University Ravensburg, Germany
}

\begin{abstract}
This paper explores three different learning approaches, namely Problem Based Learning, Project Oriented Learning and Design-Build-Test experiences. The general research interest is to demonstrate how the development of these learning approaches effects learning achievement. The focus of this study is directed towards design-related subjects and especially Engineering Design education. More specifically, the paper works on the hypothesis that the opportunity to build and test products is a prerequisite for constructive and sustainable self-reflexion. The paper also examines the effect of the different learning approaches on the students' perception of who is giving them feedback. Therefore, the findings from a comparative survey among 82 second year students in Engineering Design are shared and discussed.
\end{abstract}

Keywords: Problem-based learning, project-oriented learning, design-build-test experiences, engineering design education, comparative survey

\section{INTRODUCTION}

In previous work we have studied intensively in how far it is important for the learning process that Engineering Design students do not just plan products but also get the opportunity to build and test them $[1,2,3,4,5]$. The findings indicate that - although already a lot of things can be learned by pure paperwork - there are at least some critical learning outcomes that cannot be addressed without the physical realisation of products $[6,7]$. One important learning mechanism that helps to gain experience in a field, relies on learning from own mistakes [7]. Therefore, this study is about the beneficial effects of creating a free space in the learning process that allows 'gentle failure'.

\section{LEARNING APPROACHES}

Since the Roman philosopher, politician, dramatist and natural scientist SENECA [8] provoked his disciple LUCILIUS with his (inversely formulated) famous saying ${ }^{1}$, discussions among teachers on sustainable ways of transferring things learned in school for use in real life have never broken off (not even literally two millennia later). More recently, psychologists coined the term 'situated learning' to point out this 'transfer failure'. The reason why an immediate transfer often fails is based on the phenomenon that 'knowing something is closely tied into a context, and when we... remove the knowledge or skill from its context, we no longer have the same situation and therefore no longer have the same response' [9]. Various pedagogies try to make learners overcome this inherent obstacle. In our study, we concentrate on Problem-Based and Project-Oriented Learning as well as Design-Build-Test experiences. In the following, these learning approaches are listed in decreasing order of general applicability (depicted by the hierarchic arrangement in form of a stepped model in Figure 1). Thus, studying real-world problems (Problem-Based Learning) embodies the most important approach in contemporary tertiary education. Often, but not necessarily, this goes along with working on a project-oriented basis (Project-Oriented Learning). On top of that, design-related disciplines offer the opportunity not only to study a problem in a project-oriented way but also to enable the learners to build and test (Design-Build-Test experiences) the products they have designed (at least as a prototype).

\footnotetext{
'Non vitæ sed scholæ discimus!' (We do not learn for life, but for school!)
} 


\subsection{Problem-Based Learning}

The concept of Problem-Based Learning (PBL) was developed and made popular in the 1960's and fosters self-guided learning [10]. It is often shortly defined as a 'learn to learn' concept [11, p. 117]. The worth of 'learning through problem situations' is described to be 'much more effective than memorybased learning' [ibid]. The problems must be sufficiently challenging that students cannot solve them with existing knowledge so new knowledge must be generated with the help of the facilitator [12, p. 3]. In all Engineering disciplines this pedagogical practice can be well established. A typical example of a problem studied in Engineering Design lectures in current Mechanical Engineering programmes is the design of a gearbox where students receive individual datasets.

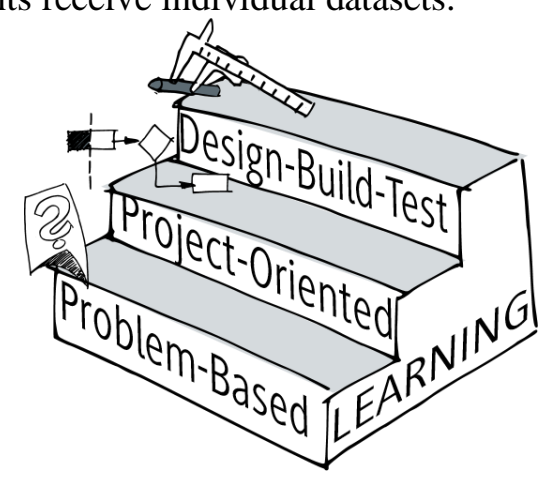

Figure 1. Learning approaches applied in the study

\subsection{Project-Oriented Learning}

Project-Oriented Learning (POL) strives to add another dimension to the learning outcomes. This approach - basically described as 'learning by doing' by many authors, e.g. [13, p. 292] - accustoms students to assume different project roles in a sort of 'role play' and thus strengthens competences needed in their later professional life. Like Problem-Based Learning, this pedagogy also starts from presenting ill-defined, open-ended problems.

\subsection{Design-Build-Test experiences}

In contemporary engineering education CRAWLEY et al. [14] observe 'a seemingly irreconcilable tension between... the ever-increasing body of technical knowledge that graduating students must master... [and the] wide array of personal and interpersonal skills.' In response to this shortcoming, the CDIO initiative [15] - an international educational network - formulates that the chief concern for engineering faculties should be to form students that are able to 'conceive, design, implement and operate real-world systems and products'. For the sake of simplicity, we call the learning set-up into which students are projected within the domain of Engineering Design for Design-Build-Test experiences (DBT). The rationale behind this approach - where students design, build and test products on their own - is that students should be able to learn from their 'product' (and not exclusively from their teacher) by observing if their design decisions have turned a product into functioning in the way they have designed it for [3].

\section{METHODOLOGY}

The comparative survey in hand works out differences in how students that work with the three presented learning approaches (Problem-Based Learning, Project-Oriented Learning and Design-Build-Test experiences) perceive the learning feedback they get and how they deal with own mistakes.

\subsection{Context}

DHBW Cooperative State University offers engineering education programmes that markedly promote alternative learning approaches. Expressed in accredited workload, Engineering Design takes an important position throughout the whole three-year long bachelor's programme in Mechanical Engineering. This article reports on a third semester lecture on Machine Elements that is supplemented by an Engineering Design Project. Technically, the course focuses on the dimensioning of roller bearings, shafts and shaft components. A critical point for enabling a large cohort of students to make DesignBuild-Test experiences at an individual level was the quick manufacturing of parts. Therefore, some 
students were instructed to build their designed products entirely with help of 3D printers (using Fused Filament Fabrication technology [16, p. 147f, 17]).

\subsection{Levels of Treatment}

In analogy to clinical studies, the survey compares the effect of different 'levels of treatment' which the participants 'received'; cf. e.g. [18]. In our case, the participants were 'exposed' to different learning approaches. We were particularly interested in how far the physical realisation of a product is a conditio sine qua non (i.e. a prerequisite) for learning from own mistakes. Correspondingly, the participants have been split into a study group (receiving active 'treatment') and a control group (with 'placebo treatment').

\subsection{Participants}

We conducted our comparative survey among 82 second year students in Engineering Design. The participants were spread over four classes. Two classes also built and tested the products they had designed in their Engineering Design project. In analogy to clinical studies one could say that this group of 39 students received an 'active treatment' (group A). The other two classes also worked in a projectoriented way. But the solutions they developed existed only on paper. In the comparative assessment this group serves as a reference. In clinical studies this group of 43 students would be called the 'placebo group' (group P).

\subsection{Data Collection and Measurement}

Data were collected by means of a questionnaire. The participants filled in the questionnaire in class, after a short intervention explaining the study. Luckily, the study obtained a response rate of $100 \%$ of the distributed questionnaires. The questionnaire contained five questions (on one single page) and is composed of a ranking, several assessments on LIKERT-type scales and an open question with a table to fill in.

\section{RESULTS}

In this study we are mainly interested in the effect of the learning approach on the (perceived) learning feedback and also wanted to know if some learning approaches facilitate to establish an 'inner (selfregulatory [19, p. 67]) control loop' in learning better than approaches others do.

\subsection{Who is giving feedback on learning achievements?}

One complex of questions in the survey tried to find out where the students get their feedback from and inquired about quantitative as well as qualitative aspects.

From a quantitative point of view, we asked the students to rank from what source they received most feedback on the quality of their design. This question provided four alternatives to choose from: the feedback of the educator during the lectures, conversations with peers, functional testing with the designed product and the final grading at the end of the project, see Figure 2.

As expected, students that were also able to test their products (group A), state that educators do not at all play the leading role, corresponding to an averaged rank of only 3.4 (of the four possible choices) in Figure $2 \mathrm{~b}$. Instead, students indicate that the best feedback they got comes directly 'from the product' (1.4 in average). The intermediate positions are held by the students' peers (with an average of 2.2), followed by the final grading at the end of the project (2.6).

As completely opposed to this, the control group $(\mathrm{P})$ 'swapped' the importance in the feedback from the educator and from the product. Group P (that only designed their products on paper but did not get the opportunity to build and test them) attributes the most importance for giving feedback to the educator, corresponding to the average rank of 1.7 in Figure 2a. The product itself as source of feedback ended way behind (3.4). Like in the study group (A), the students' peers finish second (with an average of 2.1) level pegging with the final grading (2.2).

This answers of group P would not surprise in a 'classical' teacher-centred learning set-up. But it is less easy to explain why this happens in student projects that are based on real-world problems and involve project management. The results suggest that in design-related projects teacher-centrism is hard to break up with respect to feedback on the learning achievement if not the product is built and tested. 


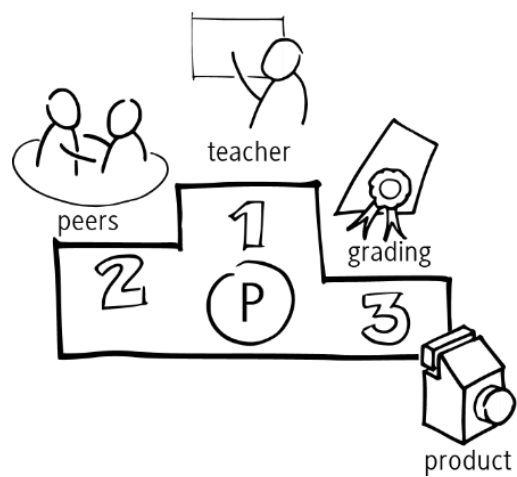

(a)

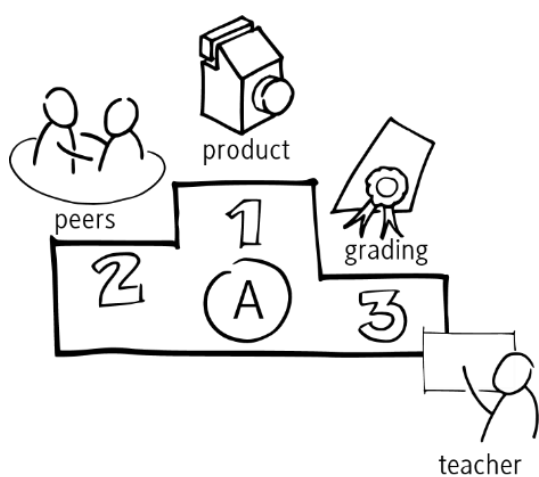

(b)

Figure 2. Quantitative ranking of the feedback received by the students from different sources in the a) control group ('placebo treatment') and in the b) study group ('active treatment')

But what do students think about the quality of the feedback they received from the four different sources (teacher, peers, grading, product)? And is this opinion effected by the learning approach the students worked with?

For this reason, we asked the participants to rate on a psychometric scale in how far the feedback was understandable and traceable for them. The corresponding values on the scale were reaching from 1 (meaning that the feedback was very good) to 5 (indicating insufficient feedback). Figure 3 a shows the average ratings from the control group $(\mathrm{P})$ and the study group $(\mathrm{A})$ in absolute values. The effect of the learning approach can be studied by looking at the differences between the two groups. Therefore, we subtract the average rating of the study group (A) from the average rating of the control group $(\mathrm{P})$ for each item, see Figure $3 b$. For all sources of feedback except one the differences are very small, i.e. the difference is less than $20 \%$ of a step size on the five-point scale $(|\Delta| \leq .2)$. The direct product feedback stands out in either way - regarding the differences as well as the absolute values. Students having built and tested the products they have designed assess the direct product feedback significantly to be better ( $\Delta=1.3$ ) compared to those who have not had the opportunity. Moreover, direct product feedback also attains the best result in absolute terms (with an average value of 1.6 on the scale).

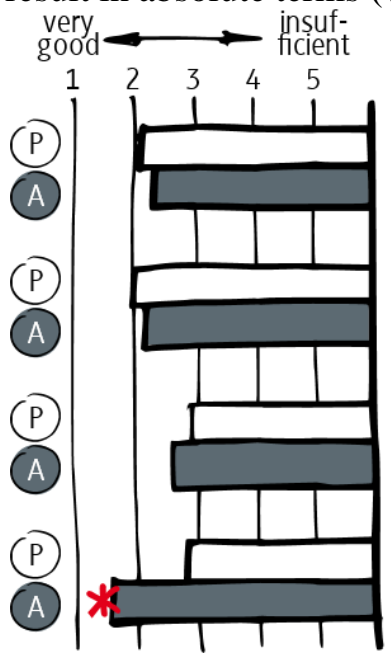

(a)

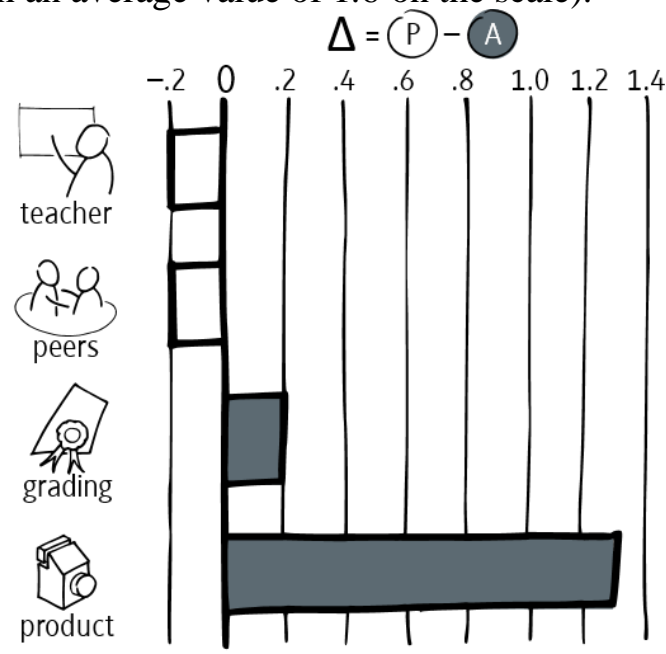

(b)

$P$ control group ('placebo treatment'), $A$ study group ('active treatment')

Figure 3. Qualitative assessment of the feedback received by the students from different sources: a) absolute values and b) differences

\subsection{Does the learning approach foster learning from own mistakes?}

In this second complex of questions, we wanted to know from the students in both groups if they have made mistakes during the design of the product (results in Figure 4a). Another question requested the participants to state whether they have got the feeling that they have learned something from their own mistakes or not (Figure $4 b$ ). 
Asking students if they have committed mistakes in a project naturally puts them into a dilemma. Even more because their learning is embedded in an educational system that provides that their personal learning achievement is assessed at the end of the term. So, on one hand, they surely do not wish to detract from their achievement in the project. On the other hand, they will be led in their answers by what they think that the questioner desires to hear to present themselves as 'reflective thinkers'.

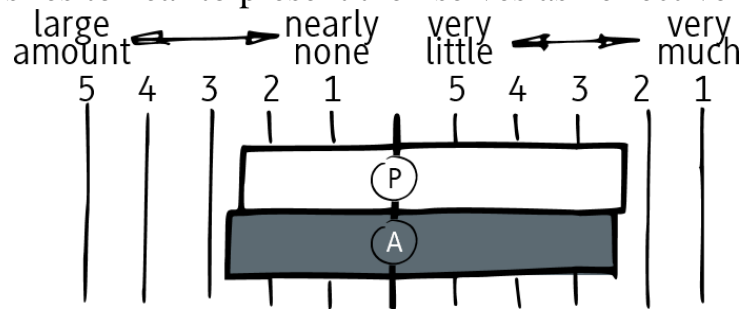

(a)

(b)

$P$ control group ('placebo treatment'), $A$ study group ('active treatment')

Figure 4. Self-perception of dealing with mistakes:

a) mistakes made, and b) lessons learned

According to our expectation, the replies did not differ between both groups. For that reason, we also requested the students to enumerate design faults by jotting down a few notes on (a) what went wrong in the design, (b) to what defects this design fault led and (c) how they rectified the problem. The questionnaire provided a $3 \times 3$ matrix where students could fill in three potential mistakes and describe the mistakes closer according to the provided categories (a)-(c). Figure 5 counts the average number of cases that the students filled in that table.

The quantitative difference between the control group (1.7 cases filled in average) and the study group (5.9) is evident. But looking through the results in detail also reveals an enormous difference in the quality of the answers. Students from the group that had just designed a product but did not build and test it (P), just brought forward some project-related deficiencies but were almost unable to name concrete design faults. In significant contrast to the control group P, students that also personally tested their products (group A) could give a substantially more detailed account of failures in their designs and could tell how to improve it.

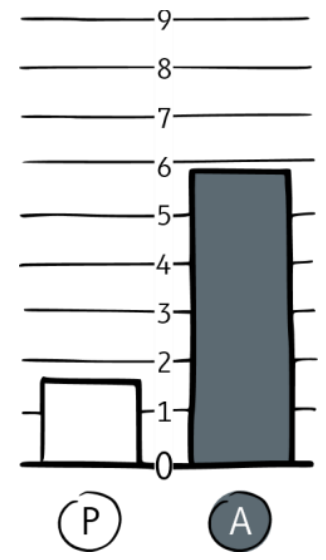

\section{$P$ control group ('placebo treatment'), $A$ study group ('active treatment')}

Figure 5. Number of cases filled

\section{DISCUSSION AND CONCLUSION}

The results of the quantitative ranking of who is giving the students feedback may astonish at first sight. Has not an educator who is not perceived as the main source of feedback by her/his students done a bad job? But looking closer into the learning context shows us that the only way to act as a learning facilitator is to step back a little from the limelight. The comforting message for those educators who still are anxious about this change of roles is that - limelight or background - there is no alteration in the students' qualitative perception of the feedback.

Another finding of the study is that answers about own mistakes are rather governed by what the respondent thinks that the questioner desires to hear than by implications from the learning context. Opposed to that, an indirect question has revealed interesting insights. The results indicate that building 
and testing products (instead of just designing them on paper) allows a deeper self-regulatory reflexion of learning achievements, and thus promotes a culture of constructive self-criticism in Engineering Design projects.

\section{REFERENCES}

[1] Voß M., Bozkurt H. and Sauer T. Make your bed and lie in it! Learning to take the consequences of design decisions in an Engineering Design project. In International Conference on Engineering and Product Design Education, E\&PDE'15, Loughborough, September 2015, pp.400-405 (The Design Society, Glasgow).

[2] Voß M. and Bozkurt H. On a scalable Design-Build-Test experience that challenges students and staff. In EAEEIE Annual Conference, EAEEIE'15, Copenhagen, July 2015, (European Association for Education in Electrical and Information Engineering).

[3] Voß M., Bozkurt H. and Sauer T. Grading Engineering Design Projects. Let products give feedback! In International Conference on Engineering and Product Design Education, E\&PDE'16, Aalborg, September 2016, pp.442-447 (The Design Society, Glasgow).

[4] Sauer T., Voß M., Bozkurt H. and Nutzmann M. Experiences with Direct Product Feedback in courses on Engineering Design. In International Conference on Engineering and Product Design Education, E\&PDE'18, London, September 2018, pp.50-55 (The Design Society, Glasgow).

[5] Voß M., Bozkurt H. and Sauer T. Aligning assessment results with learning outcomes. In International Conference on Engineering and Product Design Education, E\&PDE'17, Oslo, September 2017, pp.424-429 (The Design Society, Glasgow).

[6] Voß M. Students Response to open-ended problems in an Engineering Design Project. In International Conference on Engineering and Product Design Education, E\&PDE'12, Antwerp, September 2012, pp.343-348 (The Design Society, Glasgow).

[7] Voß M., Bozkurt H. and Sauer T. How students perceive different learning approaches. In EAEEIE Annual Conference, EAEEIE'18, Reykjavík, September 2018, (Institute of Electrical and Electronics Engineers, New York).

[8] Seneca L.A. Epistulae morales ad Lucilium, 62, ep.106.12.

[9] Svinicki M. and McKeachie W.J. McKeachie's Teaching Tips. Strategies, Research, and Theory for College and University Teachers. 2011 (Wadsworth, Belmont, CA).

[10] Barrows H. S. Problem-Based Learning in Medicine and Beyond. A Brief Overview. New Directions for Teaching and Learning, 1996, 68, 3-12.

[11] Butan D. Case Studies in Problem-Based Learning in Engineering. In International Symposium for Engineering Education, ISEE'07, Dublin, September 2007, pp.117-121.

[12] Matusovich H.M., Paretti M.C., Jones B.D. and Brown P.R. How Problem-Based Learning and Traditional Engineering Design Pedagogies Influence the Motivation of First-Year Engineering Students. In Annual Conference of the American Society for Engineering Education, ASEE'12, January 2012, San Antonio, TX, paper 25.702, pp.1-17.

[13] Awang, D. Comparison between Project-Oriented Learning and Problem-Based Learning in Design Subject. In Regional Conference on Engineering Education, RCEE'07, Johor Bahru, December 2007, pp.290-295.

[14] Crawley E.F., Malmqvist J., Östlund S., Brodeur D.R. and Edström K. Rethinking Engineering Education. The CDIO Approach, 2014 (Springer, Cham).

[15] The CDIO website. Available: http://www.cdio.org/ [Accessed on 2020, 09 March].

[16] Gibson I., Rosen D. and Stucker B. Additive Manufacturing Technologies. 3D Printing, Rapid Prototyping, and Direct Digital Manufacturing, 2015 (Springer, Berlin).

[17] Ultimaker 2+ Specification Sheet. (Ultimaker B.V., Geldermalsen).

[18] Bacchieri A. and Della Cioppa G. Fundamentals of clinical research. 2007 (Springer, Milano).

[19] Zimmerman B.J. Becoming a self-regulated learner. An overview. In Theory into practice, 2002, 41(2), 64-70. 